\title{
Morphometric study of Acipenser naccarii (Bonaparte, 1836) in fish farm individuals
}

\author{
By J.A. Hernando ${ }^{1}$, G. Arlati, A. Domezain, M. C. Soriguer, L.A. Poliakova-Belysceva, J. Domezain, C. Vallespín and \\ R. Bravo \\ Grupo Dinámica de poblaciones de peces y Departamento de Biología Animal, Biología Vegetal y Ecologia. Facultad de Ciencias del \\ Mar. Universidad de Cádiz. 11510 Puerto Real (Cádiz, Spain)
}

\section{Summary}

The main objective of this study was to analyse differences and similarities in morphometric characteristics among specimens of the same year class of Acipenser naccarii (Bonaparte, 1836), comparing fish raised either in Italy or Spain. All specimens were F1 of captive broodstock in Italy.

Fifteen biometric variables were measured, and three derived indices were calculated, on 30 individuals of $3+$ year class from Lombardy (Italy) and 90 individuals of $1+, 2+$ and $3+$ year class from Riofrío (Granada, Spain). A stepwise discriminate analysis (SDA) was carried out, and the results were contrasted using a non-hierarchical cluster analysis. The two groups proved to be similar, so a principal component analysis and a simple regression analysis were performed on all individuals, taking total length (T1) as the independent variable and all the biometric variables as dependent.

The study revealed that although the Soljan index (i.e. ratio of mouth width to snout length) is related to $\mathrm{Tl}$, and is a valid taxonomic characteristic, the CA index (i.e. relative position of the barbels) and FB index (i.e. ratio of snout length to width) are also valid characteristics for individuals longer than $57 \mathrm{~cm}$, being independent of $\mathrm{Tl}$.

\section{Introduction}

In Italy there is a captive broodstock of Acipenser naccarii (Bonaparte, 1836) at the Azienda Agricola VIP (Orzinuovi, Brescia), upon which controlled reproduction has been successfully performed since 1988 (Arlati et al. 1988). Specimens of this Italian stock have been imported to Riofrío (Granada, Spain). Recently, it has been reported that Acipenser naccariii may be autochthonous to Spain and Portugal (Garrido-Ramos et al. 1997; Hernando et al. 1997), in agreement with historical Portuguese reports on its presence in rivers of the Iberian Peninsula (Capello, 1859 and 1880; Osorio 1894; Seabra 1911; Nobre 1931 and 1935; Gonçalves 1942, Helling 1943; Alburquerque 1956).

The objective of the present study was to assess any possible effects on the determinant characteristics of the species caused by the conditions of cultivation, and to study the possible taxonomic characteristics that might be subject to allometric variation.

\section{Materials and Methods}

A total of 120 individuals of Acipenser naccarii (Bonaparte, 1836) were divided into four groups of 30 individuals each, corresponding to age classes of $1+, 2+$ and $3+(2$ groups $)$. Of this total, the 30 individuals obtained from the Orzinuovi fish farm (Lombardy, Italy) belonging to age class $3+$ formed one group and the remaining 90 individuals, from the Sierra Nevada fish farm (Riofrio, Spain) were separated into three groups of age classes $1+, 2+$ and $3+$; the cultivation conditions of the groups are shown in table 1 . All individuals were F1 of wild stock parentage from the Adriatic. The parentage of the groups of $1+, 2+$ y $3+$ are all different, with no group sharing either father or mother; however, those individuals of age classes $3+$ from Orzinuovi and Riofrio have the same parentage.
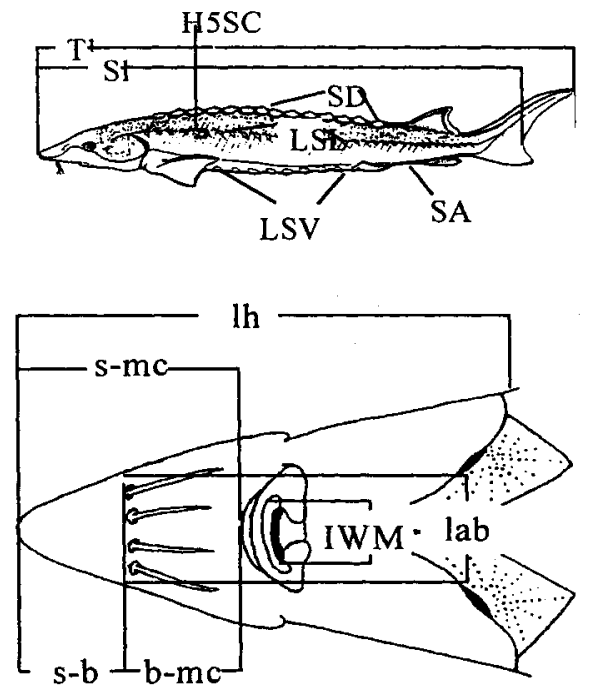

Fig 1.- Body and head morphometric characteristics on a schematic representation of an Acipenser naccarii, modified after Holcik et al (1989), used in this study. In accordance with the nomenclature used by Soljan (1975) and Holcik et al. (1989): TI, Total length; SI, standard length; W, weight; s-b, distance from snout to the base of the barbels; lab, width of the snout at the height of the barbels; b-mc, distance from the base of the barbels to the cartilaginous arch of mouth; s-mc, distance from the tip of snout to the cartilaginous arch of mouth; hl, length of the head. Scute series: anal, AS; dorsal, DS; left, LLS; lateral right, RLS; ventral left, LVS; ventral right, RVS; IWM, intemal width of mouth

Fourteen biometric variables (Fig 1) described by Holcik et al. (1989), 1 by Soljan (1975) and the height of the 5th scute (H5SC) were measured, and three indices, based on Sokolov's (1989) key for the identification of species of the genus Acipenser, were calculated. In accordance with the nomenclature used by Soljan (1975) and Holcik et al. (1989), variables measured were: Tl (Total length), SI (standard length), W ( weight), s-b (distance from snout to the base of the barbels), lab (width of the snout at the height of the barbels), b-mc (distance from the base of the barbels to the cartilaginous arch of mouth) s-mc (distance from the tip of snout to the cartilaginous arch of mouth), hl (length of the head). Scute series: anal (AS), dorsal (DS), lateral (left LLS and right RLS), ventral (left LVS and right RVS) and IWM (internal width of mouth). The indices were defined in order to determine the relative position of the barbels (CA) by calculating the difference between $b$ $\mathrm{mc}$ and $\mathrm{s}-\mathrm{b}: \mathrm{CA}=\mathrm{b}-\mathrm{mc}-\mathrm{s}-\mathrm{b}$; the ratio of s-mc to lab, as FB = s-mc : lab, and the ratio of mouth widths to snout length, referred to as the Soljan index (SOLJ) $=$ s-mc : IWM. Statistical analyses were carried out using STATGRAPHICS ${ }^{\mathrm{TM}}$ and BMDPTM. 
Table 1.- Conditions of fish culture of the Riofrio (RF) and Orzinuovi (OR) specimens used for this study. The Feed data are expressed as the percentage of the animal weight supplied as feed per day; the two percentage figures shown for the group $3+$ from OR correspond to the quantities of feed supplied in winter and summer, respectively

\begin{tabular}{|c|c|c|c|c|c|c|c|c|c|}
\hline Group & $\begin{array}{c}\text { Tank size } \\
\text { (m) }\end{array}$ & $\begin{array}{c}\text { Material of } \\
\text { tank walls }\end{array}$ & $\begin{array}{l}\text { Material of } \\
\text { tank bottom }\end{array}$ & $\begin{array}{c}\text { Maximum } \\
\text { temperatur } \\
\mathrm{e} \\
\left({ }^{\circ} \mathrm{C}\right)\end{array}$ & $\begin{array}{l}\text { Minimum } \\
\text { temperature } \\
\left({ }^{\circ} \mathrm{C}\right)\end{array}$ & Oxygen & Feed & $\mathrm{pH}$ & $\begin{array}{l}\text { Photoperiod } \\
\text { Ilumination }\end{array}$ \\
\hline $\mathrm{I}+\overline{\mathrm{RF}}$ & $20 \times 3 \times 0.7$ & Smooth cement & Smooth cement & 16 & 14.5 & Saturation & $1.5 \%$ & $7.4-7.6$ & natural in RF \\
\hline $2+\& 3+\mathrm{RF}$ & $50 \times 6 \times 1$ & Smooth cement & Gravel & 18 & 13.5 & $80-100 \%$ & $1 \%$ & $7.3-7.6$ & natural in RF \\
\hline $3+\mathrm{OR}$ & $25 \times 6 \times 0.6$ & Smooth cement & Sand & 18 & 10.5 & $75-100 \%$ & $\begin{array}{c}0.65 \% \\
\text { and } 1.2 \%\end{array}$ & $7.4-7.6$ & natural in $O R$ \\
\hline
\end{tabular}

\section{Results}

Firstly, it was considered necessary to investigate differences and similarities between individuals of the same age class raised in Italy or Spain. This was achieved using Stepwise Discriminant Analysis (SDA; BMDP7M) on the $3+$ individuals from the two origins. Two groups were established a priori and all the variables were used. Statistical analysis confirmed the existence of two groups separated according to H5SC (height of the 5th scute; $\mathrm{I}=0.016 ; \mathrm{F}=2933.91$; $\mathrm{DF}=1,48)$, as a first canonical variable and by s-mc $(1=0.009 ; \mathrm{F}=$ 2555.98; $\mathrm{DF}=2,47$ ) without needing to use any other variable (Fig. 1). In view of these results, SDA was performed again but this time omitting the scute variables and separating the remaining variables into two groups according to IWM $(1=0.553 ; F=38.77 ; \mathrm{DF}=1$, 48). Previous assignment of individuals to each group (Italy, Riofrio) were successful in $24 \%$ and $26 \%$ of cases, respectively (Fig. 2).

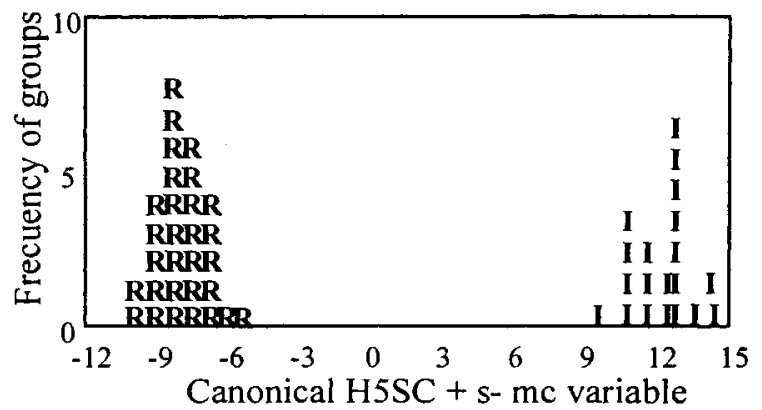

A

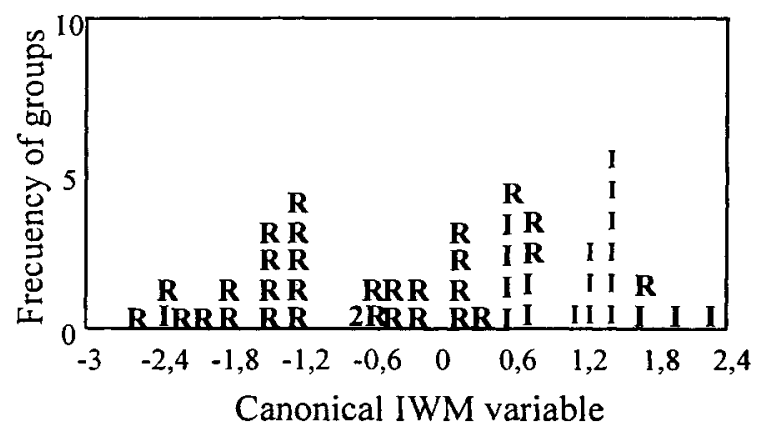

B

Fig 2.- A.- Histogram of canonical variables separating Italian group (positive values) from Riofrio group (negative values), on plane defined for two groups and using distances calculated by Mahalanobis method and using all the variables. $\mathrm{H} 5 \mathrm{SC}$, height of the 5 th scute; s-mc, distance from the tip of snout to the cartilaginous arch of mouth. B.- Histogram of canonical variables separating Italian group (positive values) from Riofrio group (negative values), on plane defined for two groups and using distances calculated by Mahalanobis method and without scute variables. IWM, internal width of mouth
These results were verified by applying non-hierarchical cluster analysis (BMDPKM; K-means clustering of cases) to 60 individuals and using $\mathrm{Tl}, \mathrm{CA}, \mathrm{FB}$ and $\mathrm{SOLJ}$ as distinguishing variables. Mean distances for each group and variable are given in table 2. According to this statistical procedure, there was clearly only one group that extended along the first axis. This permitted the 120 individuals to be studied as a single sample.
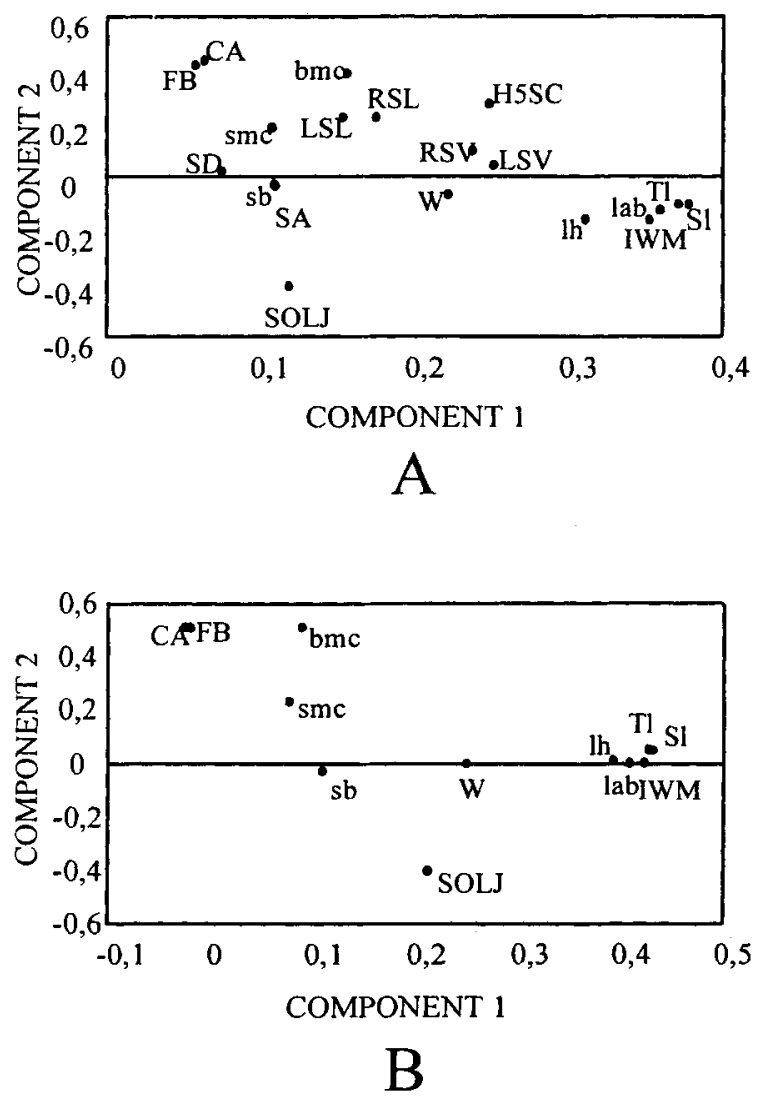

Fig 3.- A.- Plot of weight of principal components using all variables.

B.- Plot of weight of principal components using variables without scutes series. Tl, Total length; Sl, standard length; $\mathrm{W}$, weight; $\mathrm{s}-\mathrm{b}$, distance from snout to the base of the barbels; lab, width of the snout at the height of the barbels; b-mc, distance from the base of the barbels to the cartilaginous arch of mouth; s-mc, distance from the tip of snout to the cartilaginous arch of mouth; hl, length of the head. Scute series: anal, AS; dorsal, DS; left, LLS; lateral right, RLS; ventral left, LVS; ventral right, RVS; IWM, internal width of mouth

Principal Components Analysis (PCA; BMDP4M) was carried out on all the individuals using all the variables. The first three axes corresponded to $65.9 \%$ of the total variance, producing only one group that extended along the first axis defined by $\mathrm{Tl}$ and related 
variables (Sl, IWM and lab) and by $\mathrm{CA}$ and $\mathrm{FB}$. The remaining variables b-mc, s-b, and SOLJ were dispersed between both groups of variables (Fig. 3A and table 3). The PCA (Principal Components Analysis) without the scute variables accounted for $85.2 \%$ of the total variance and the groups of variables and dispersion could not distinguish different groups (Fig 3B and table 4).

Table 2.- Results of the non-hierarchical cluster analysis (BMDPKM; Kmeans clustering analysis), for $\mathrm{Tl}, \mathrm{CA}, \mathrm{FB}$ and SOLJ (Key: see figure 1 and text)

\begin{tabular}{cccccc}
\hline GROUP & SIZE (\%) & Tl & CA & FB & SOLJ \\
\hline Italian & 24 & 104.19 & 0.667 & 1082 & 0.801 \\
Riofrio & 26 & 91.81 & -1.19 & 0.967 & 0.754 \\
F-ratio & & 53.9 & 2.302 & 73.93 & 1.9 \\
P-value & & 0 & 0.136 & 0 & 0.175 \\
\hline
\end{tabular}

Tl, Total length; $C A=b-m c-s-b ; F B=s-m c: l a b ; S O L J=s-m c: I W M$ where $b-m c=$ distance from the base of the barbels to the cartilaginous arch of mouth; $\mathrm{s}-\mathrm{b}=$ distance from snout to the base of the barbels; $s-\mathrm{mc}$ $=$ distance from the tip of snout to the cartilaginous arch of mouth; lab = width of the snout at the height of the barbels; IWM = internal width of mouth

Table 3. Factor loadings (pattern) extracted by the Principal Component Analysis (PCA) using all variables

\begin{tabular}{lcc}
\hline Variables & $\begin{array}{c}\text { Component } 1 \\
\text { (Lengths) }\end{array}$ & $\begin{array}{c}\text { Component 2 } \\
\text { (Indices) }\end{array}$ \\
\hline b-mc & 0.1556 & 0.3869 \\
CA & 0.0635 & 0.4347 \\
FB & 0.0575 & 0.4170 \\
H5SC & 0.2472 & 0.2720 \\
lab & 0.3594 & -0.1285 \\
hl & 0.3105 & -0.1621 \\
IWM & 0.3524 & -0.1655 \\
Sl & 0.3780 & -0.1062 \\
TI & 0.3712 & -0.1056 \\
W & 0.2212 & -0.0696 \\
AS & 0.1098 & -0.0370 \\
s-b & 0.1091 & -0.0295 \\
DS & 0.0753 & 0.0197 \\
RLS & 0.1744 & 0.2214 \\
LLS & 0.1528 & 0.2235 \\
S-mc & 0.1074 & 0.1821 \\
SOLJ & 0.1185 & -0.4128 \\
RVS & 0.2370 & -0.0951 \\
LVS & 0.2504 & -0.0412 \\
\hline
\end{tabular}

$\mathrm{Tl}$, Total length; Sl, standard length; W, weight; s-b, distance from snout to the base of the barbels; lab, width of the snout at the height of the barbels; $b$ $\mathrm{mc}$, distance from the base of the barbels to the cartilaginous arch of mouth; s-mc, distance from the tip of snout to the cartilaginous arch of mouth; hl, length of the head. Scute series: anal, AS; dorsal, DS; lateral left, LLS; lateral right, RLS; ventral left, LVS; ventral right, RVS; IWM, internal width of mouth; $\mathrm{CA}=\mathrm{b}-\mathrm{mc}-\mathrm{s}-\mathrm{b} ; \mathrm{FB}=\mathrm{s}-\mathrm{mc}$ : lab; SOLJ = s-mc : IWM,

Table 4. Factor loadings (pattern) extracted by the Principal Component Analysis (PCA) using variables without scutes series

\begin{tabular}{lcc}
\hline Variables & $\begin{array}{c}\text { Component 1 } \\
\text { (Lengths) }\end{array}$ & $\begin{array}{c}\text { Component } 2 \\
\text { (Indices) }\end{array}$ \\
\hline b-mc & 0.0883 & 0.5100 \\
CA & -0.0252 & 0.5106 \\
FB & -0.0199 & 0.5083 \\
lab & 0.4084 & 0.0017 \\
hl & 0.3924 & 0.0130 \\
IWM & 0.4227 & 0.0015 \\
SI & 0.4307 & 0.0484 \\
TI & 0.4269 & 0.0502 \\
W & 0.2482 & -0.0013 \\
s-b & 0.1084 & 0.0285 \\
s-mc & 0.0766 & 0.2299 \\
SOL & 0.2112 & -0.4025 \\
\hline
\end{tabular}

Tl, Total length; SI, standard length; W, weight; s-b, distance from snout to the base of the barbels; lab, width of the snout at the height of the barbels; $b$ $\mathrm{mc}$, distance from the base of the barbels to the cartilaginous arch of mouth; $\mathrm{s}$-mc, distance from the tip of snout to the cartilaginous arch of mouth; hl, length of the head; IWM, intemal width of mouth; $C A=b-m c-s-b ; F B=s-$ mc : lab; SOLJ = s-mc : IWM

In order to determine the possible existence of relationships with $\mathrm{Tl}$, simple linear regression analysis was performed between $\mathrm{Tl}$ (independent variable) and the remaining variables (dependent variables) (Table 5). Regression lines were obtained for all the variables and were compared with the regressions of Bernini and Nardi (1989) (Table 6).

Table 5. Simple linear regression analysis between $\mathrm{Tl}$ and the remaining variables. Key: $a=$ Intercept; $b=$ slope; $; p=$ value and $r=$ correlation coefficient. Values marked with ${ }^{*}$ are not significant, therefore these variables are independent of $\mathbf{T}$ ]

\begin{tabular}{ccccc}
\hline Dependent variable & $\mathrm{a}$ & $\mathrm{b}$ & $\mathrm{p}$ & $\mathrm{r}$ \\
\hline CA & 2.4 & 0.034 & $0.0709^{*}$ & 0.0345 \\
FB & 1.067 & 0.00075 & $0.6135^{*}$ & 0.0440 \\
SOLJ & 0.397 & 0.0035 & 0 & 0.3887 \\
b-mc & 11.8457 & 0.2626 & 0.0030 & 0.2689 \\
s-mc & 4.6381 & 0.7517 & 0.0203 & 0.2125 \\
s-b & 6.9405 & 0.2886 & $0.0688^{*}$ & 0.1674 \\
\hline
\end{tabular}

$\mathrm{CA}=\mathrm{b}-\mathrm{mc}-\mathrm{s}-\mathrm{b} ; \mathrm{FB}=\mathrm{s}-\mathrm{mc}$ : lab; SOLJ = s-mc : IWM; b-mc, distance from the base of the barbels to the cartilaginous arch of mouth; s-mc, distance from the tip of snout to the cartilaginous arch of mouth; $s-b$, distance from snout to the base of the barbels; lab, width of the snout at the height of the barbels; IWM, internal width of mouth

Table 6.- Comparison of simple linear regression analyses between the variables of this study and those of studies in the Ticino and Po Rivers (Bernini \& Nardi, 1989)

\begin{tabular}{lcccc}
\hline & & THIS STUDY & TICINO & PO \\
\hline \multirow{2}{*}{ s-mc vs Tl } & a & 3.125 & -1.182 & 1.195 \\
& b & 0.311 & 0.588 & 0.583 \\
& n & 120 & 53 & 24 \\
IWM vs & a & 2.44 & 0.148 & 0.249 \\
s-mc & b & 0.342 & 1.376 & 1.239 \\
& & & & \\
IWM vs TI & n & 120 & 54 & 24 \\
& a & -1.09 & 0.075 & 0.194 \\
& n & 1.094 & 0.945 & 0.799 \\
LC vs TI & a & 120 & 53 & 24 \\
& b & 1.64 & 0.729 & 0.845 \\
& n & 120 & 0.79 & 0.767 \\
\hline
\end{tabular}

Key: $a=$ Intercept $; b=$ slope $; n=$ size of sample; $s-m c$, distance from the tip of snout to the cartilaginous arch of mouth; $\mathrm{T}$, Total length; IWM, internal width of mouth; LC

\section{Discussion}

The four groups were analysed in light of the following characteristics:

1. The three groups from the Riofrio were cultivated under one set of technological conditions, whereas the group from the Orzinuovi ( $3+\mathrm{OR})$ had different cultivation conditions.

2. Two of the four groups $(3+R F$ and $3+O R)$ were of the same parentage, but had been cultivated under different technological conditions.

3. The groups $1+, 2+$ were of different parentage from each other and from the two groups of $3+$.

The SDA results indicate that the percentage probability of correctly assigning a given individual to its group (24\% and $26 \%$ ) were low enough to reject the initial hypothesis that they constitute two groups. This conclusion was reinforced by the results obtained from the $\mathrm{K}$-means clustering of cases. The results 
obtained from the PCA revealed the same finding, since once the variables associated with length were separated out, the other variables were distributed in a single group that explained $85.2 \%$ of the total variance.

Despite the fact that the four groups differed in age, size and cultivation method, the morphological characteristics associated with the snout (b-mc, sb and $s-m c$ ) were not linked to body lengths. The independence of the CA and FB indices was also clear, although the former was only independent of total length for specimens longer than $57 \mathrm{~cm}$. Although Soljan's index was related to $\mathrm{Tl}$, all the values were less than 2, falling between 0.604 and 0.993 (Soljan 1975). This index can, therefore, be considered a valid taxonomic characteristic for this species.

\section{References}

Albuquerque, R.M., 1956: Peixes do Portugal e ilhas adjacentes. Chaves para a sua determinaçao. Portg. Acta Biologica. (B). 5-1 164

Arlati, G.; Bronzi, P.; Colombo, L.; Giovannini, G., 1988: Induzione della riproduzione nello storione italian (Acipenser naccarii) allevato in cattivitá. Riv. Ital. Acquacol. 23, 94-96

Bermini, F.; Nardi, P.A., 1989: Caracteri morfometrici e meristici del genere Acipenser L. (Osteichthyes, Acipenseridae) nel tratto pavese dei Fiumi Po e Ticino. Bolletino del Museo Regionale di Scienze Naturali. Torino. 7 (2), 321-340.

Capello, F.B., 1869: Catalogo do peixes do Portugal que existem no Museo de Lisboa.Jorn So Math Phys Nat. I" serie, 2, 131-193.

Capello, F.B., 1880: Catalogo do peixes do Portugal. Mem. Acad. R. Sc. Lisboa, 6, 1-78.
Garrido-Ramos, M.A.; Soriguer, M.C.; de la Herranz, R.; Jamilena, M.; Ruiz Rejon, C.; Domezain, A.; Hemando, J.A.; Ruiz Rejon, M. 1997: Morphometric and genetic analysis as proof for the existence of two sturgeon species in the Guadalquivir River. Marine Biology 129, 33 39.

Gonçalves, B.C. 1942: Colecçao ocenográfica de D. Carlos I.- Peixes Trav. Stat. Biol. Mar. Lisbonne, 46, 1 - 108.

Helling, H., 1943: Novo catologo dos Peixes do Portugal em colecçao do Museu de Zoologia da Universidade de Coimbra. Mem. Est. Mus. Zool. Univ. Coimbra. 149, 1-110.

Hernando, J.A.; Ruiz-Rejón, M; Soriguer, M.C.; Domezain A., 1997: Actualización de la distribución histórica de Huso huso (L. 1758) y Acipenser naccarii Bonaparte 1836: nuevos casos de regresión. II Congreso Ibérico de Biólogos Ambientalistas. Badajoz. España

Holcick, J., Banarescu, P.; Evans, D.E., 1989: A general introduction to fishes. In: The freshwater fishes of Europe. Vol 1/II. Ed. J. Holcik, AulaVerlag Wiesbaden pp: 18 - 147

Nobre, A. 1931: Peixes das aguas doces de Portugal. Bolm. Min. Agric., $13(2), 73-112$

Nobre, A., 1935: Fauna Marinha de Portugal. Vertebrados. Porto., 579 $\mathrm{pp}$.

Osorio, B., 1894: D'algunas especies a juntar ao Catalogo dos peixes do Portugal de Capello. Jorn Sc Math phys Nat.,3 (11), 186-188.

Seabra, A.F., 1911: Catalogue systmatique des vertbros du Portugal. V. Poissons. Bull. Soc. Port. Sc. Nac., 5, 129-224.

Sokolov, L.L., 1989: Acipenser Linnaeus, 1758. In: The freshwater fishes of Europe. Vol 1/1I. Ed. J. Holcik, Aula-Verlag, Wiesbaden. pp:201-205.

Soljan, T., 1975: Il pesci dell'Adriatico. Mondadori. Verona. 522 pp

\section{Acipenser naccarii $\times$ A. baerii}

This $80 \mathrm{~cm}$ hybrid displays the morphological characters more typical of $A$. baerii. The great depth to the head and body are more $A$. naccarii.

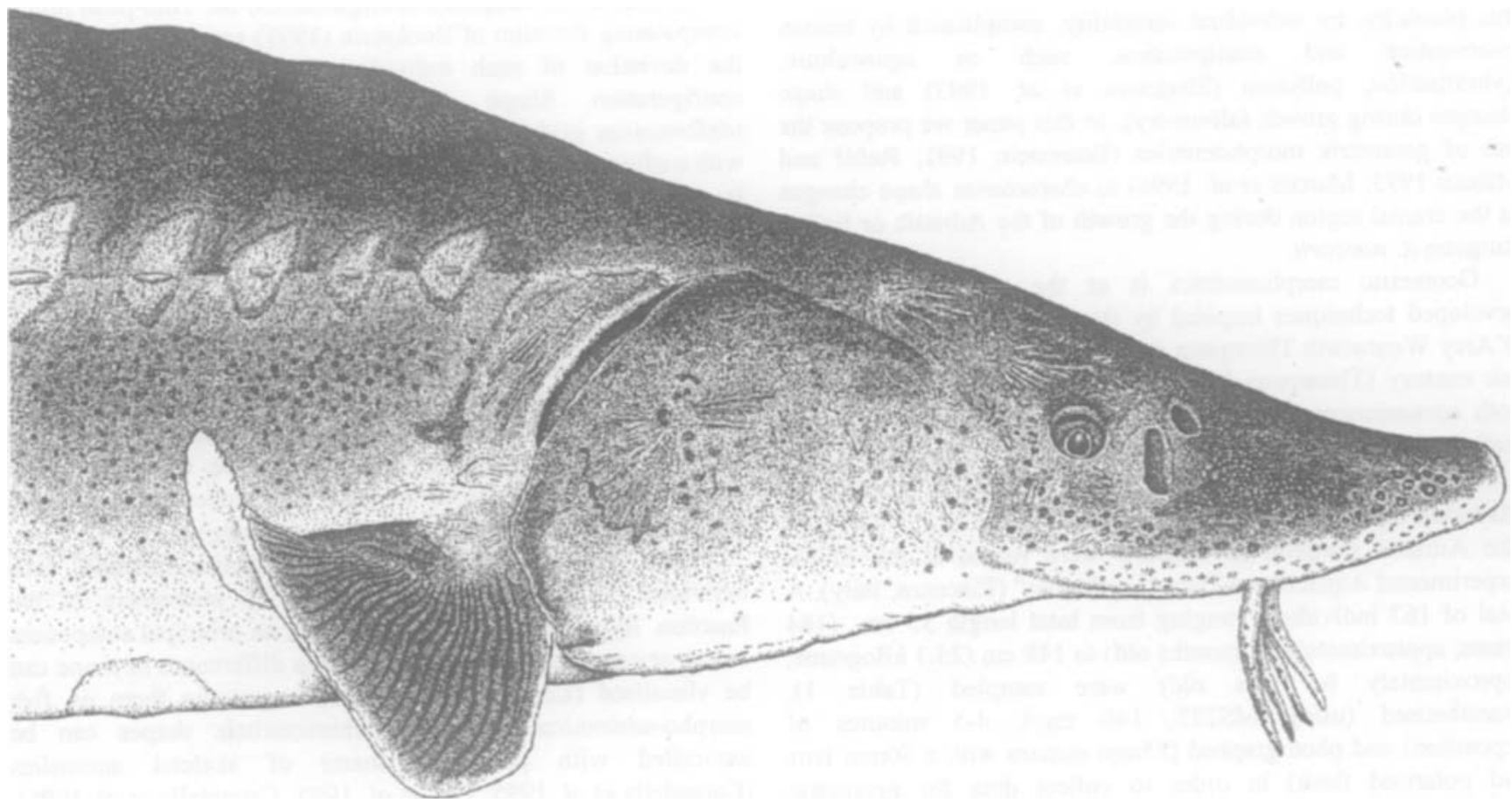

